\title{
Comparison between red-green-blue imaging and visible-near infrared reflectance as potential process analytical tools for monitoring syneresis
}

\author{
M. J. Mateo, ${ }^{*} †$ D. J. O'Callaghan, ${ }^{* 1}$ and C. P. O'Donnell† \\ ${ }^{*}$ Teagasc, Moorepark Food Research Centre, Fermoy, Co. Cork, Ireland \\ †Biosystems Engineering, School of Agriculture, Food Science and Veterinary Medicine, University College Dublin, Belfield, Dublin 4, Ireland
}

\begin{abstract}
The current work focuses on the comparison of 2 on-line optical sensing systems; namely red-greenblue imaging and visible-near infrared reflectance, for monitoring syneresis during cheese manufacture. The experimental design consisted of 3 temperature treatments carried out in an 11-L cheese vat in triplicate. Both systems were shown to predict syneresis without significant differences in prediction accuracy. However, a single-wavelength near infrared model was the most parsimonious (standard error of prediction $=4.35 \mathrm{~g} / 100$ $\mathrm{g}$ ) for predicting syneresis. This technique was also the simplest in terms of parameters in the model (standard error of prediction $=4.15 \mathrm{~g} / 100 \mathrm{~g}$ with 2 parameters), when time after gel cutting and process parameters (temperature and cutting time) were included in the models. The study showed that either system could be employed to control syneresis in cheese manufacture and improve the control of moisture content in cheese.

Key words: red-green-blue (RGB) imaging, visiblenear infrared reflectance, syneresis, cheese manufacture
\end{abstract}

\section{INTRODUCTION}

The expulsion of whey from curd accelerates after gel cutting, which is a direct consequence of curd contraction (i.e., syneresis), and its control is an essential aspect of cheesemaking (Dejmek and Walstra, 2004). Various optical and ultrasonic techniques have been used to monitor syneresis at the laboratory level (Lodaite et al., 2000; Taifi et al., 2006; Talens et al., 2009). A sensor for monitoring syneresis in commercial cheese vats would be a process analytical tool for control of curd moisture in cheese manufacture. Increasing temperature (cooking) of the curd/whey mixture enhances syneresis, which is reflected in a lower moisture content

Received September 29, 2009.

Accepted January 18, 2010.

${ }^{1}$ Corresponding author: donal.ocallaghan@teagasc.ie of cheese after pressing (Walstra, 1993; Huber et al., 2001; Thomann et al., 2008).

Several studies have recently been reported on techniques for on-line monitoring of syneresis in a cheese vat or for monitoring casein size distribution in whey:

(i) An on-line visible-near infrared (NIR) sensor was used for predicting syneresis indices, mainly curd moisture content and yield of whey, and it was concluded that this technique was adequately robust to be implemented in the cheese industry to facilitate information about critical steps to the cheesemaker (Fagan et al., 2009; Mateo et al., 2009b,c). An on-line NIR sensor at $700 \mathrm{~nm}$ was employed to determine casein particle size distribution in whey, showing potential application in industrial-scale cheesemaking (Guillemin et al., 2006).

(ii) Colorimetric technique: the potential of color techniques for monitoring yield of whey and curd moisture content has been confirmed by Everard et al. (2009), who studied the effect of milk fat level and gel firmness level on cheese curd syneresis.

(iii) Image processing techniques: these techniques involve robust on-line image capture systems in conjunction with a variety of approaches to image processing. Everard et al. (2007) studied curd syneresis over a range of $\mathrm{pH}$ and stirring speeds and found that image processing using a threshold technique had potential for monitoring syneresis indices; for example, yield of whey and curd moisture during cheesemaking. Fagan et al. (2008) studied curd syneresis over a range of milk $\mathrm{pH}$ values and stirring speeds using images captured at the surface with a range of techniques for image texture analysis, including first-order gray level statistics, gray level co-occurrence matrix (GLCM), and fractal dimension. These authors found the fractal dimension technique useful for controlling curd moisture content in cheesemaking. 
The main advantages of these techniques are that they are nondestructive and provide real-time data. Near infrared spectroscopy has been identified as an ideal process analytical technology tool, and recent publications have demonstrated the potential of this technology coupled with chemometric techniques for monitoring coagulation, syneresis, and cheese ripening (Fagan et al., 2007). Feng et al. (2007) demonstrated the potential of an automated image acquisition system for monitoring barley tempeh (a traditional Indonesian fermented food) fermentation. Cernadas et al. (2005) found that magnetic resonance imaging in conjunction with image texture analysis could be used for the sensorial quality characterization of pork products.

The aim of the present study was to compare a redgreen-blue (RGB) imaging system with a visible-NIR reflectance sensor to monitor the volume of whey produced during syneresis. This is the first direct comparison of these technologies under common experimental conditions. In both cases, the sensors were mounted below the surface of the curd/whey mixture.

\section{MATERIALS AND METHODS}

Two optical sensor technologies, namely an RGB imaging system based on a digital camera and a visible-NIR reflectance sensor, were installed in an 11-L laboratory-scale cheese vat (Pierre Guerin Technologies, Mauze, France). Two image-processing techniques (threshold and GLCM) were used to process the RGB images. These were compared with 2 light reflectance approaches; that is, single-wavelength NIR and broadspectrum visible-NIR techniques, for predicting volume of whey over a range of temperature treatments during syneresis.

\section{Experimental Design}

The experimental design consisted of 3 temperature treatments carried out in triplicate. Each treatment was defined in terms of renneting temperature and final temperature. In two of the treatments, the temperature was held constant, at 32 or $38^{\circ} \mathrm{C}$, throughout renneting and stirring. The other treatment involved a cooking step, where renneting occurred at $32^{\circ} \mathrm{C}$ and the temperature was increased by $1^{\circ} \mathrm{C}$ every $5 \mathrm{~min}$, beginning at 5 min after gel cutting, until a final temperature of $38^{\circ} \mathrm{C}$ was reached.

\section{Milk Preparation and Coagulation}

Whole milk was recombined to a total solids level of $12 \%$ with a target fat level of $3.0 \%$ ( $\mathrm{SD}=0.08 \%$, wt $/$ wt) in the cheese vat in 2 stages. On the day before renneting, low-heat skim milk powder $(6.25 \mathrm{mg}$ of undenatured whey protein nitrogen/g of skim milk powder; Teagasc, Co. Cork, Ireland) was recombined with distilled water at $42^{\circ} \mathrm{C}$ while being stirred at $44 \mathrm{rpm}$. Following cooling to $8^{\circ} \mathrm{C}$, the milk was held overnight under gentle agitation conditions (10 rpm).

On the day of renneting, cream (Dairygold, Cork, Ireland) was added at $20^{\circ} \mathrm{C}$ while the milk was stirred at $44 \mathrm{rpm}$ for $5 \mathrm{~min}$. Calcium chloride $\left(\mathrm{CaCl}_{2} \cdot 2 \mathrm{H}_{2} \mathrm{O}\right)$ was then added to the milk at $2.04 \mathrm{mmol} / \mathrm{L}$ while being stirred at $44 \mathrm{rpm}$ for $5 \mathrm{~min}$.

Milk pH was measured at renneting temperature; that is, 32 or $38^{\circ} \mathrm{C}$ depending on the treatment. Thirty milliliters of milk was removed from the cheese vat to analyze milk composition (fat, protein, and lactose contents) using a MilkoScan 605 (Foss Electric, Hillerød, Denmark). Milk was clotted by adding $0.18 \mathrm{~g}$ of chymosin (Chy-Max Extra, EC 3.4.23.4, isozyme B, 600 international milk clotting units/mL, Chr. Hansen Ireland Ltd., Cork, Ireland) in a 10\% dilution in reverse osmosis water per kilogram of milk at $32^{\circ} \mathrm{C}$, and the mixture was stirred continually at $31 \mathrm{rpm}$. Stirring was stopped after $3 \mathrm{~min}$ and the stirrers were replaced with twin cutting blades in readiness for gel cutting.

At all stages, vat temperature was controlled by circulation of water between a water bath (Grant Y28, Grant Instruments Ltd., Cambridge, UK) at 32 or $38^{\circ} \mathrm{C}$ $\pm 0.1^{\circ} \mathrm{C}$ and a heating jacket on the vat.

\section{Gel Cutting Determination and Procedure}

Small amplitude oscillatory rheometry was performed within the linear viscoelastic region at a frequency of $1 \mathrm{~Hz}$ and a strain of amplitude 0.02 to determine the gel cutting time $\left(\boldsymbol{t}_{c u t}\right)$ using an AR 2000 EX Rheometer (TA Instruments, Crawley, UK; Mateo et al., 2009c). A concentric cylinder system was used with $5.92 \mathrm{~mm}$ of clearance beneath the bob (bob diameter $=26 \mathrm{~mm}$ and cup diameter $=28 \mathrm{~mm}$ ). A 20-mL sample of milk was taken from the cheese vat at $3 \mathrm{~min}$ after rennet addition and immediately transferred to the rheometer cup that was prewarmed to the required temperature. After temperature equilibration of the milk sample and bob, measurements were taken every $30 \mathrm{~s}$.

A fixed cutting program (8.3 revolutions of the cutting blades) was used to cut the gel when the elastic modulus $\left(\mathrm{G}^{\prime}\right)$ reached $35 \mathrm{~Pa}$. Four minutes after gel cutting, the knives were replaced with the twin stirrers to agitate the curd/whey mixture at $22 \mathrm{rpm}$ as described in Mateo et al. (2009a). Then, in the case of cooking step, the temperature was increased by $1^{\circ} \mathrm{C}$ every 5 min until the temperature reached $38^{\circ} \mathrm{C}$. 


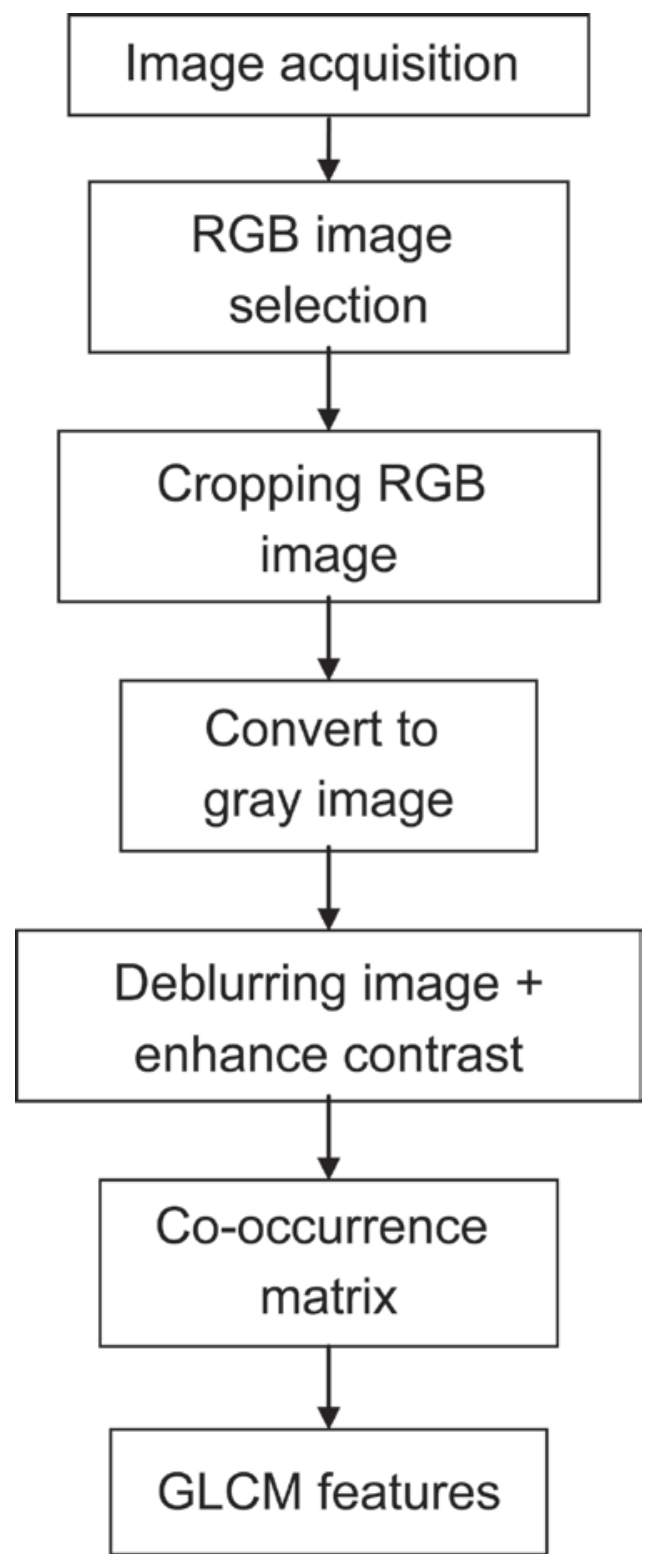

Figure 1. Flow diagram of curd/whey mixture red-green-blue (RGB) image processing according to the gray level co-occurrence matrix (GLCM) technique.

\section{Determination of Whey Yield}

An on-line sampler was used for removing curd and whey samples from the vat (Everard et al., 2008; Mateo et al., 2009b). The curd/whey mixture was separated using a stainless steel sieve with a $300-\mu \mathrm{m}$ absolute pore size and pan (Endecotts Ltd., London, UK) to facilitate fast draining of the whey. Whey samples were taken for compositional analysis at $t=5$ min and every 10 min thereafter up to $t=75$ min (i.e., 8 samples). Whey yield $\left(\boldsymbol{Y}_{w}\right)$ was determined by weighing the pan contents after draining and expressing this as a percentage of the total contents of the pan and the sieve, as described in Mateo et al. (2009c). Because the mass of curd + whey is equivalent to a mass of milk, $Y_{w}$ is expressed in grams of whey per 100 grams of milk.

\section{Image Processing System}

An RGB imaging system includes a digital image capture system (camera), with image storage, processing, communication, and display (Feng et al., 2007). The image acquisition system consisted of a digital camera (Canon A75) mounted externally on a tripod. Images of the curd/whey mixture were captured through a sightglass (diameter of $5 \mathrm{~cm}$ ) in the vat wall; the sight-glass separated the wet material in the vat from the dry area outside the vat where the camera was installed. The illumination system used a low-noise fiber optic illuminator working at high intensity (model 9741-52, Cole Parmer Instrument Co., Chicago, IL) and 2 light guides to direct the light at the curd/whey mixture through the sight glass. The system was calibrated using a gray card positioned over the glass window installed in the cheese vat to adjust the light before each trial. The same camera settings were used across all trials.

\section{Image Processing Techniques}

The images acquired in each trial were processed in sequence using Matlab software (Matlab 7.6.0.324, R2008a, The MathWorks Inc., Natick, MA) with the image processing toolbox. Images were selected for processing, coinciding with the time of sampling of curd and whey. Each image was processed as follows: the image was cropped to display a cross-section of curd within the vat window. The cropped image was converted from RGB to grayscale, deblurred by using a Wiener filter, and then enhanced using contrast-limited adaptive histogram equalization (Figure 1). Two different image processing techniques, GLCM and threshold, were applied to these grayscale images.

Second-order statistical techniques such as GLCM take into account the spatial relationship between pixels (Zheng et al., 2006; Fagan et al., 2008). Using GLCM in this study, 21 features [autocorrelation (autoc), contrast (contr), correlation (corrp), cluster prominence (cprom), cluster shade (cshad), dissimilarity (dissi), energy (energy), entropy (entro), homogeneity (homom), maximum probability (maxpr), sum of squares (sos), sum average (savgh), sum variance (svarh), sum entropy (senth), difference variance (dvarh), difference entropy (denth), information measure of correlation (inf1h or inf2h), inverse difference normalized (indnc), inverse difference moment normalized (idmnc)] were extracted and used to develop the models. Some of these features are defined in Zheng et al. (2006). 


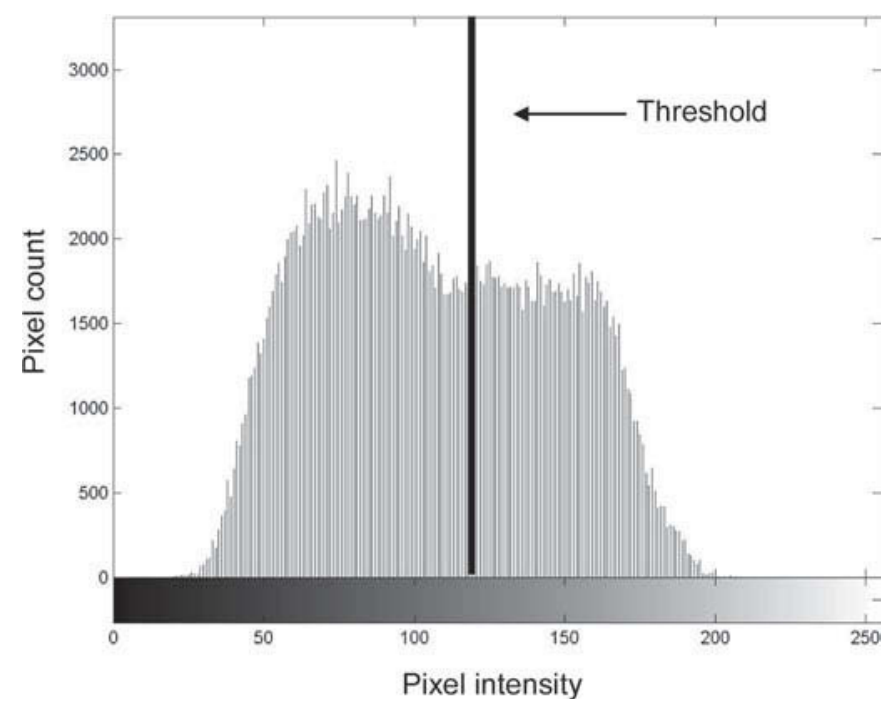

Figure 2. A typical histogram plot of intensity distribution in a digital image, showing a threshold value of 120 , which is used to reconstruct the image as a silhouette of suspended curd particles. This is done by replacing each pixel whose gray level is $>120$ with one color and representing all other pixels in another color. The areas of curd and whey in the image are calculated as the percentage of pixels with each color.

The threshold technique, which is a simple and fast technique for characterizing image regions as silhouettes based on gray level (Brosnan and Sun, 2004), was then applied to distinguish between curd and whey (Figure $2)$. Finally, the image parameters; that is, the white area $\left(\mathrm{A}_{\mathrm{w}}\right)$ representing curd, the yellow area $\left(\mathrm{A}_{\mathrm{y}}\right)$ representing whey, and the ratio $\left(\mathrm{R}_{\mathrm{wy}}\right)=\mathrm{A}_{\mathrm{w}} / \mathrm{A}_{\mathrm{y}}$, were calculated at 3 threshold levels (100, 120, and 140, respectively), which were selected to partition the histogram of intensity distribution into 2 overlapping peaks.

\section{Visible-NIR Sensor Technology}

An on-line visible-NIR sensor technology was used to carry out this study as described in Mateo et al. (2009b). This sensor used a 6-W tungsten halogen light source (model LS1B, Ocean Optics Inc., Dunedin, FL), which transmitted to the curd/whey mixture through a fixed large-diameter $(5 \mathrm{~mm})$ optical fiber (Fiberoptics Technology Inc., Pomfret, CT), a vertical polarizer (Edmund Optics Inc., Barrington, NJ), and a glass window (20 mm diameter). Backscattered light was collected through the glass window and was transmitted through a second fiber ( $5 \mathrm{~mm}$ diameter) and a collimating lens (Edmund Optics Inc.) that focused the scattered light onto a $\sim 800-\mu$ m-diameter fiber optic cable (Spectran Specialty Optics, Avon, CN) to the master unit of a miniature fiber optic spectrometer (HR2000CG-UVNIR, Ocean Optics B.V., Duiven, the Netherlands), which was used as a light detector. Both single-wave- length NIR (980 nm) and broad-spectrum visible-NIR $(189-1,100 \mathrm{~nm})$ approaches were investigated in this study. In the single-wavelength approach, the light reflectance ratio $\left(\boldsymbol{R}^{\prime}\right)$ was calculated by dividing the light reflectance signal from the detector at $980 \mathrm{~nm}$ by a reference value obtained in milk before gelation. This was averaged over 17 successive points (Mateo et al., 2008).

\section{Statistical Analysis}

Matlab (version 7.6.0.324, R2008a; The MathWorks Inc.) software was used to extract the image texture features from the selected images. Regression techniques were used to predict $Y_{w}$ produced during syneresis using a visible-NIR sensor and RGB imaging techniques, respectively. To identify the significant parameters that were included in each model, multiple linear regression was used in SigmaStat software (Version 3.1, Systat Software Ltd., London, UK), and partial least squares (PLS) regression was used to develop models with an optimum number of loadings in The Unscrambler software (v9.2, Camo Process AS, Oslo, Norway; Naes et al., 2002).

The prediction ability of a model developed through this process is inferred from the standard error of prediction (SEP), where $\mathrm{SEP}^{2}=$ mean square error $=$ sum of squared residuals/df, where $\mathrm{df}=$ degrees of freedom (Naes et al., 2002). Models were compared for prediction ability using a statistical test on the residuals; that is, an $F$-test for equal variances, carried out in Minitab software (Minitab 15, Minitab Ltd., Coventry, UK). Preference was given to a model having a smaller number of factors (or loadings), where there is no significant difference in SEP. Range error ratio (RER) was calculated by dividing the range of the response variable by the SEP of the prediction model. This is sometimes used to determine the practical utility of models (De Marchi et al., 2009; Fagan et al., 2009).

All the regression models developed in this study were tested for statistical assumptions (normality and equal variance), and any model that failed such a test or with $\mathrm{R}<0.7$, was discarded.

\section{RESULTS AND DISCUSSION}

\section{Comparison of Predictive Models for $Y_{w}$ Produced During Syneresis}

The predictive ability of the 2 sensing techniques (i.e., NIR and RGB imaging) was assessed by the fit of models developed using each sensing technique for $Y_{w}$ (Table 1). The models are arranged in order of increasing SEP, and where applicable, the parameters involved 
in each model are listed in order of decreasing Student's $\mathrm{t}$-value, which is calculated by dividing the regression coefficient by its standard error. The R-values show that each model explains between 60 and $72 \%$ of the variation in the data. This illustrates the limitations of correlation as a measure of assessing the utility of prediction models (Workman and Mark, 2004). The SEP values were in a narrow range (4.35 to $5.60 \mathrm{~g} / 100 \mathrm{~g}$ ). The range of RER values in Table 1 is between 6.63 and 8.5. According to De Marchi et al. (2009), these models indicate limited to good practical utility.

Surveying all the models listed in Table 1, it was found that NIR model 1.1 was the most parsimonious model with only one parameter, $R^{\prime}$, and $\mathrm{SEP}=4.35$ $\mathrm{g} / 100 \mathrm{~g}$. The broad-spectrum model 2.1, GLCM model 3.1, and threshold model 3.1 ( $\mathrm{SEP}=4.79,4.84$, and $5.07 \mathrm{~g} / 100 \mathrm{~g}$, respectively) did not differ significantly in fit compared with model 1.1, according to the $F$-test for equal variance of the residuals. Across this table, it can be observed that no significant differences in fit occurred between the 2 GLCM models 3.1 and 3.2 [with 6 parameters (i.e., features) and 5 PLS loadings, respectively] and model 4.1 (threshold model). From these findings, it was concluded that the single wavelength technique had adequate robustness to be implemented on an industrial scale. Previous studies were carried out over a range of different experimental variables (curd cutting program, curd stirring speed, and milk fat level), and they confirmed the potential of a single wavelength sensor to monitor whey production (Mateo et al., 2009b,c). The most useful feature or wavelength over all of the factors used in the development of the models was the $980 \mathrm{~nm}$ wavelength because it is easier to implement at an industrial level, is less sensitive to interference from stray light, and can be implemented using an energy-efficient, low-cost light source such as laser-LED.

However, RGB imaging techniques could be a good alternative to the single wavelength technique for the different requirements of the cheese industry (i.e., variations in milk fat content). The current work did not investigate the variation of milk fat content, but earlier studies demonstrated that this variation can be measured with more accuracy using a broad-spectrum visible-NIR sensor or color coordinates computer system (Everard et al., 2008; Mateo et al., 2009c).

\section{Comparison of Predictive Models for $Y_{w}$ Produced During Syneresis Using RGB Imaging Techniques or NIR Sensor in Combination with Technological Parameters}

The highest rate of syneresis occurs during the first 15 min after gel cutting, after which syneresis decreases

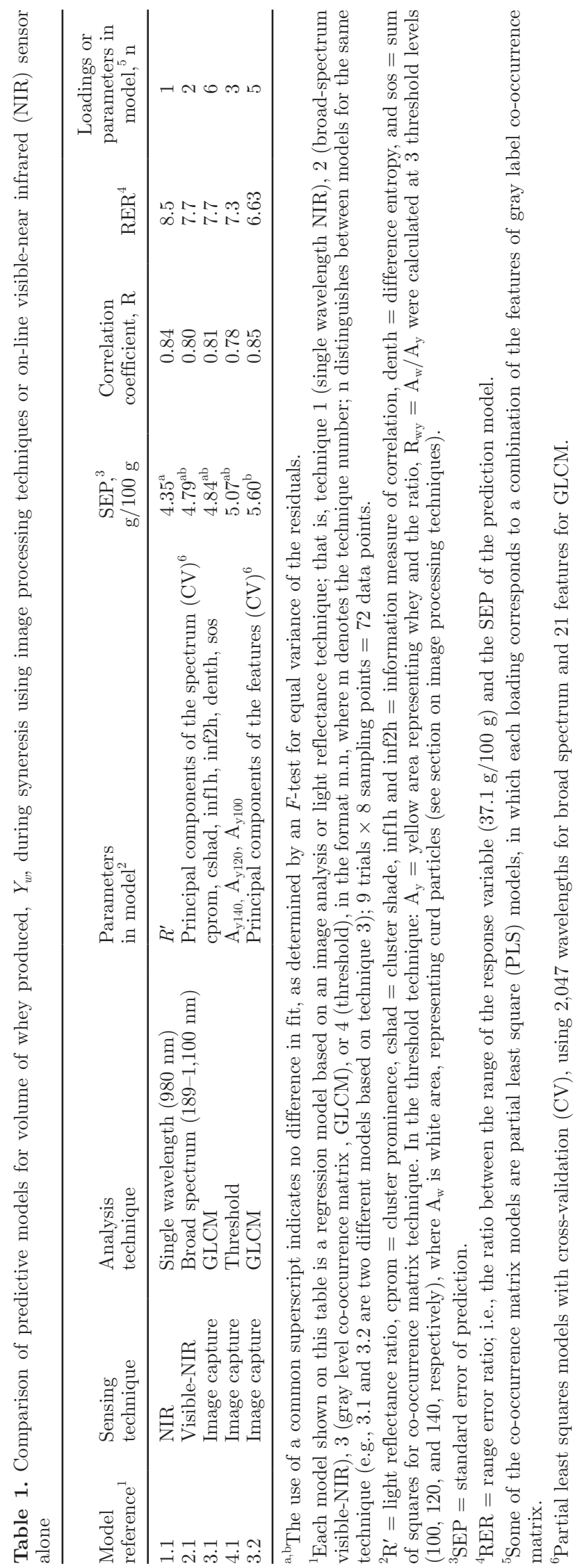

Journal of Dairy Science Vol. 93 No. 5, 2010 


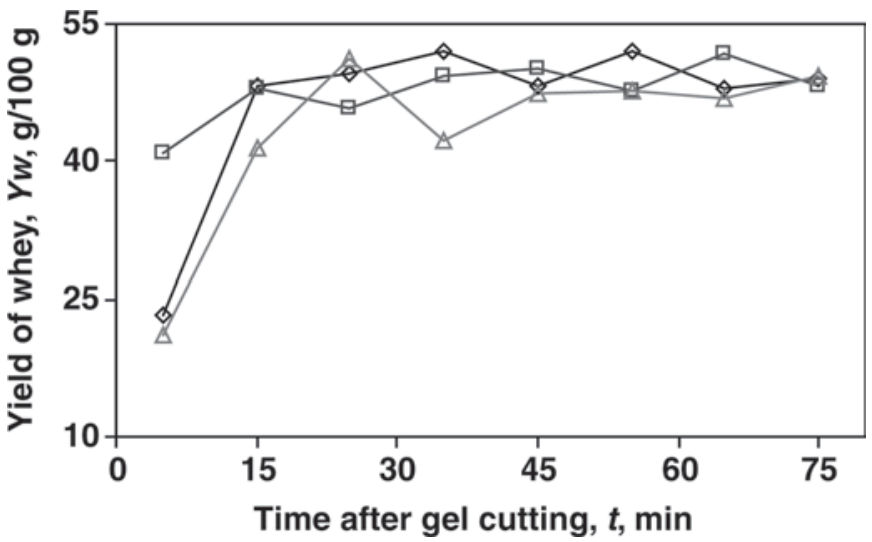

Figure 3. Trend of yield of whey $\left(Y_{w}\right)$ with time after gel cutting, $t$, for 3 typical trials under different temperature treatments, namely $32^{\circ} \mathrm{C}\left(-\diamond^{-}\right), 38^{\circ} \mathrm{C}(-\square-)$, and 32 to $38^{\circ} \mathrm{C}\left(-\Delta^{-}\right)$.

rapidly (Figure 3). As can be observed from a comparison of treatments, there is little evidence of an effect of temperature. Models were developed combining each sensing technique with time after gel cutting and known process parameters to investigate possible improvements in predicting $Y_{w}$ (Table 2). As in Table 1 , the parameters in each model are shown in order of decreasing significance. The R-values show that each model explains between 62 and $77 \%$ of the variation in the data. The SEP values are in a narrow range $(3.85$ to $5.04 \mathrm{~g} / 100 \mathrm{~g}$ ). The range of RER values in Table 2 is between 7.4 and 9.6. According to De Marchi et al. (2009), these models indicate limited to good practical utility.

Five of the image processing models in Table 2 are based on the threshold method. Model 4.2 gave the lowest SEP over all the threshold models $(\mathrm{SEP}=3.85$ $\mathrm{g} / 100 \mathrm{~g})$. When the 5 threshold models were compared, it was found that models 4.2 and 4.3 did not differ significantly in fit. The same observation was concluded when models 4.3 to 4.6 were compared. Comparing these models with threshold model 4.1 in Table 1, we observed that the inclusion of time after gel cutting and cutting time significantly improved the fit in model 4.2, but no improvement was found in the other threshold models.

Single wavelength model 1.2 did not differ significantly in fit from model 4.2 and GLCM model 3.3, but the single wavelength model is more robust for industrial implementation with only 2 factors (light reflectance ratio and time after gel cutting). This observation confirms previous findings that demonstrate the potential and sophistication of this technique (Mateo et al., 2009b,c). The inclusion of time after gel cutting in model 1.2 did not improve the fit compared with models 1.1 and 2.1 according to the $F$-test on the residuals.
The same observation was found when model 3.3 was compared with model 3.1. When time after gel cutting and process parameters were analyzed, a wavelength of $980 \mathrm{~nm}$ was again an important factor in predicting $Y_{w}$ (Table 2). Ratio between white area and yellow area with a threshold value of 120 was also significant predictor for $Y_{w}$ according to Student's t value.

\section{Implications for Industrial Implementation}

A broad-spectrum, visible-NIR sensor (189 to 1,100 $\mathrm{nm}$ ) has a wide range of absorption bands, corresponding to water and other chemical bonds. This would be an advantage over a single-wavelength system in which milk is not standardized before cheese manufacture. However, when milk is standardized in composition, a single wavelength would suffice and would be a more robust solution in such a situation.

Visible NIR reflectance is more mature than RGB imaging for industrial implementation, as a robust sensor with sanitary design has recently been developed and is commercially available. To facilitate industrial adoption of visible-NIR reflectance for syneresis monitoring, validation on the pilot or commercial scale is required.

Although image capture systems are not as fully developed as visible-NIR spectroscopy for monitoring syneresis, this technology has been demonstrated as being suitable for monitoring syneresis in this study and can provide further additional advantages, such as visual inspection of a cheese vat and information on distribution of curd grain size.

The use of RGB imaging for monitoring syneresis needs to be investigated over a range of milk composition parameters to investigate the robustness of the technique taking seasonal variation into account and for manufacturing a product mix with a defined range of composition. Further development is required to realize the full potential of this technology, including enhancement of the optics/illumination/magnification system into an integrated process prototype unit that is robust, sanitary, and cleanable in place.

\section{CONCLUSIONS}

The 2 systems evaluated in this work were shown to predict syneresis without significant difference in prediction accuracy, although a single-wavelength NIR model was the most parsimonious for predicting syneresis. Both systems have potential as useful process analytical tools for implementation in the cheese industry for control of curd moisture at the point of drainage; for example, by adjusting the time of drainage or the vat temperature. Implementation of these tools could 


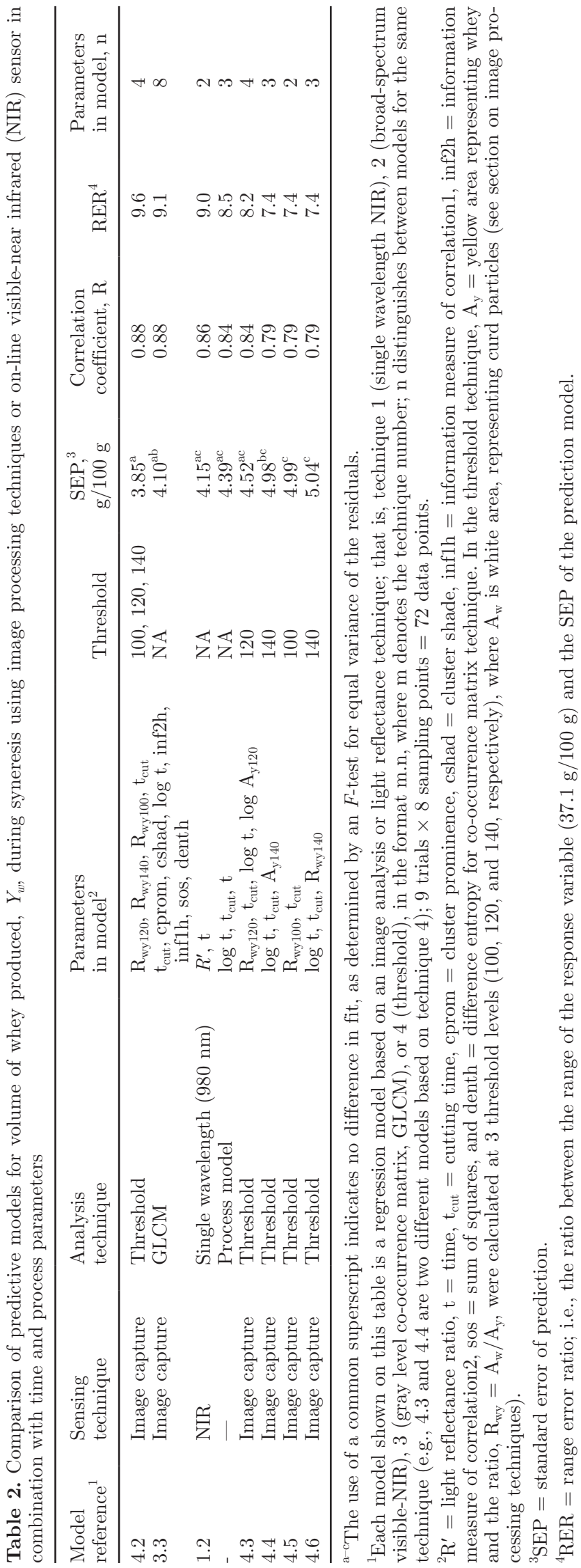

provide benefits to the cheese industry, such as better online process control, improved product consistency, continuous feedback to plant operators, and potential for increased operational efficiency during manufacturing, coupled with reduction in downgraded cheese. In summary, this study addresses some of the key challenges necessary to develop and implement a solution for on-line monitoring of syneresis, thus assisting the dairy industry toward full implementation of a process analytical control strategy.

\section{ACKNOWLEDGMENTS}

Funding for this research was provided under the Food Institutional Research Measure (FIRM) by the Irish Department of Agriculture, Fisheries and Food as part of the National Development Plan.

\section{REFERENCES}

Brosnan, T., and D.-W. Sun. 2004. Improving quality inspection of food products by computer vision-A review. J. Food Eng. 61:316.

Cernadas, E., P. Carrión, P. G. Rodriguez, E. Muriel, and T. Antequera. 2005. Analyzing magnetic resonance images of Iberian pork loin to predict its sensorial characteristics. Comput. Vis. Image Underst. 98:345-361.

De Marchi, M., C. C. Fagan, C. P. O’Donnell, A. Cecchinato, R. Dal Zotto, M. Cassandro, M. Penasa, and G. Bittante. 2009. Prediction of coagulation properties, titratable acidity, and $\mathrm{pH}$ of bovine milk using mid-infrared spectroscopy. J. Dairy Sci. 92:423-432.

Dejmek, P., and P. Walstra. 2004. The syneresis of Rennet-coagulated Curd. Pages 71-103 in Cheese: Chemistry, Physics and Microbiology. Vol. 1: General Aspects. 3rd ed. P. F. Fox, P. L. H. McSweeney, T. M. Cogan, and T. P. Guinee, ed. Elsevier Academic Press, London, UK.

Everard, C. D., C. C. Fagan, C. P. O'Donnell, D. J. O'Callaghan, M. Castillo, and F. A. Payne. 2007. Computer vision and colour measurement techniques for inline monitoring of cheese curd syneresis. J. Dairy Sci. 90:3162-3170.

Everard, C. D., D. J. O'Callaghan, M. J. Mateo, C. P. O'Donnell, M. Castillo, and F. A. Payne. 2008. Effects of cutting intensity and stirring speed on syneresis and curd losses during cheese manufacture. J. Dairy Sci. 91:2575-2582.

Everard, C. D., D. J. O'Callaghan, M. J. Mateo, C. P. O'Donnell, M. Castillo, and F. A. Payne. 2009. The use of colour parameters derived from an online fibre-optic sensor to monitor curd syneresis during cheesemaking. J. Food Eng. 94:1-6.

Fagan, C. C., M. Castillo, D. J. O'Callaghan, F. A. Payne, and C. P. O'Donnell. 2009. Visible-near infrared spectroscopy sensor for predicting curd and whey composition during cheese processing. Sens. Instrum. Food Qual. 3:62-69.

Fagan, C. C., C.-J. Du, C. P. O'Donnell, M. Castillo, C. D. Everard, D. J. O'Callaghan, and F. A. Payne. 2008. Application of image texture analysis for online determination of curd moisture and whey solids in a laboratory-scale stirred cheese vat. J. Food Sci. $73: 250-256$.

Fagan, C. C., C. Everard, C. P. O'Donnell, G. Downey, E. M. Sheehan, and C. M. Delahunty. 2007. Evaluating mid-infrared spectroscopy as a new technique for predicting sensory texture attributes of processed cheese. J. Dairy Sci. 90:1122-1132.

Feng, X. M., J. Olsson, M. Swanberg, J. Schnürer, and D. Rönnow. 2007. Image analysis for monitoring the barley tempeh fermentation process. J. Appl. Microbiol. 103:1113-1121. 
Guillemin, H., I. C. Trelea, D. Picque, B. Perret, T. Cattenoz, and G. Corrieu. 2006. An optical method to monitor casein particle size distribution in whey. Lait 86:359-372.

Huber, P., B. Fertsch, R. Schreiber, and J. Hinrichs. 2001. Dynamic model system to study the kinetics of thermally-induced syneresis of cheese curd grains. Milchwissenschaft 56:549-552.

Lodaite, K., K. Östergren, M. Paulsson, and P. Dejmek. 2000. Onedimensional syneresis of rennet-induced gels. Int. Dairy J. 10:829-834.

Mateo, M. J., C. D. Everard, C. C. Fagan, C. P. O'Donnell, M. Castillo, F. A. Payne, and D. J. O'Callaghan. 2009a. Effect of milk fat concentration and gel firmness on syneresis during curd stirring in cheese-making. Int. Dairy J. 19:264-268.

Mateo, M. J., D. J. O'Callaghan, C. D. Everard, M. Castillo, F. A. Payne, and C. P. O'Donnell. 2009c. Validation of a curd syneresis sensor over a range of milk composition and process parameters. J. Dairy Sci. 92:5386-5395.

Mateo, M. J., D. J. O'Callaghan, C. D. Everard, C. C. Fagan, M. Castillo, F. A. Payne, and C. P. O'Donnell. 2009b. Influence of curd cutting programme and stirring speed on the prediction of syneresis indices in cheese-making using NIR light backscatter. Food Sci. Technol. 42:950-955.

Mateo, M. J., D. J. O'Callaghan, C. D. Everard, C. P. O'Donnell, C. C. Fagan, M. Castillo, and F. A. Payne. 2008. Using light backscatter at $980 \mathrm{~nm}$ to determine curd moisture content at various milk fat and gel firmness levels in cheese-making. Paper number 084542 in Proc. 2008 ASABE Annual International Meeting, Providence, Rhode Island.

Naes, T., T. Isaksson, T. Fearn, and T. Davies. 2002. A User-Friendly Guide to Multivariate Calibration and Classification. NIR Publications, Chichester, UK.

Taifi, N., F. Bakkali, B. Faiz, A. Moudden, G. Maze, and D. Décultot. 2006. Characterization of the syneresis and the firmness of the milk gel using an ultrasonic technique. Meas. Sci. Technol. 17:281-287.

Talens, C., D. J. O'Callaghan, C. D. Everard, C. C. Fagan, M. Castillo, F. A. Payne, and C. P. O'Donnell. 2009. Evaluation of an improved tracer method to monitor cheese curd syneresis at varying milk fat levels in a cheese vat. Milchwissenschaft 64:161-164.

Thomann, S., A. Brechenmacher, and J. Hinrichs. 2008. Strategy to evaluate cheesemaking properties of milk from different goat breeds. Small Rumin. Res. 74:172-178.

Walstra, P. 1993.The syneresis of curd. Pages 41-191 in Cheese: Chemistry, Physics and Microbiology, Vol. 1. 2nd ed. P. F. Fox, ed. Chapman \& Hall, London, UK.

Workman, J., and H. Mark. 2004. Comparison of goodness of fit statistics for linear regression, Part II. Spectroscopy 19:29-33.

Zheng, C., D.-W. Sun, and L. Zheng. 2006. Recent applications of image texture for evaluation of food qualities - A review. Trends Food Sci. Technol. 17:113-128. 